\title{
Endometrial Neoplasm
}

National Cancer Institute

\section{Source}

National Cancer Institute. Endometrial Neoplasm. NCI Thesaurus. Code C3012.

A benign, borderline, or malignant neoplasm that affects the endometrium. 